REGARDS

SUR LEECONOMIE ALLEMANDE

BULLETIN ECONOMIQUE DU CIRAC

\section{Regards sur l'économie allemande}

Bulletin économique du CIRAC

$88 \mid 2008$

Varia

\title{
Mittelstand : les PME moins optimistes pour l'avenir
}

Isabelle Bourgeois

\section{OpenEdition}

Journals

Édition électronique

URL : http://journals.openedition.org/rea/1683

DOI : 10.4000/rea.1683

ISBN : 978-2-8218-0872-0

ISSN : 1965-0787

Éditeur

CIRAC

Édition imprimée

Date de publication : 1 octobre 2008

Pagination : 37-38

ISSN : 1156-8992

Référence électronique

Isabelle Bourgeois, « Mittelstand: les PME moins optimistes pour l'avenir », Regards sur l'économie allemande [En ligne], 88 | octobre 2008, mis en ligne le 01 octobre 2010, consulté le 15 septembre 2020. URL : http://journals.openedition.org/rea/1683

Ce document a été généré automatiquement le 15 septembre 2020

(C) CIRAC 


\title{
Mittelstand : les PME moins optimistes pour l'avenir
}

\author{
Isabelle Bourgeois
}

1 Les PME allemandes gardent le moral, bien qu'elles commencent à ressentir plus nettement l'impact du ralentissement conjoncturel mondial et, maintenant, les premiers effets de la crise financière. C'est ce qu'il ressort de la vague d'automne du climat des affaires dans le Mittelstand, publiée le 6 octobre par la fédération bancaire Creditreform.

\section{Pessimistes et optimistes presque à égalité}

2 En un an, le climat s'est légèrement dégradé. La part de ceux qui pensent que, pour leur entreprise, la marche des affaires est « très bonne ou bonne » a baissé de 4,9 points en un an, s'établissant à $46,9 \%$ seulement à la fin septembre. Globalement, la part de ceux qui l'estiment « insuffisante ou mauvaise » n'a toutefois pas augmenté dans la même proportion, passant seulement de $4,0 \%$ à $5,4 \%$. C'est dans les services que le pessimisme a gagné le plus de terrain : la part des satisfaits a baissé de 8,6 points pour tomber tombant à $47,7 \%$.

\section{Néanmoins une confiance foncière dans la compétitivité du Mittelstand}

Bien que, depuis la réalisation de ce baromètre, la situation financière se soit détériorée, cette répartition à quasi-parité des opinions positives et négatives laisse toujours entrevoir cette bonne part de confiance qu'ont traditionnellement les patrons des PME allemandes dans la compétitivité de leur entreprise. Mais ils voient leur environnement devenir moins porteur, ce qui se traduit par un tassement de leur chiffre d'affaires. Il reste toutefois modéré, puisqu'un bon tiers des 4000 entreprises interrogées $(34,7 \%)$ ont pu au contraire l'accroître au cours du semestre écoulé. Elles 
sont certes moins nombreuses que voici un an (-3,8 points), mais dans le même temps, le nombre de celles qui ont vu décroître leur chiffre d'affaires, qui s'établit à 19,1\%, n'a pas baissé dans la même proportion (de 2,8 points seulement). Une seule ombre sérieuse au tableau : la hausse du CA a été le fait du BTP et du commerce, alors que la baisse affectait la production manufacturière et les services.

Les perspectives se sont assombries pour toutes les PME. Seules 29,0\% d'entre elles envisagent avec optimisme le semestre à venir, c'est-à-dire s'attendent à une hausse de leur CA. Elles étaient encore $31,2 \%$ à l'automne dernier. La part des pessimistes s'est accrue dans les mêmes proportions, passant en un an de 11,4 \% à 15,9\%. Si le commerce est la branche la plus optimiste, et en son sein, tout particulièrement le commerce de détail (30\% des patrons attendent une hausse de leur CA, soit 3 points de plus en un an), à l'opposé, la production manufacturière se montre aujourd'hui plus prudente.

\section{Les PME restent créatrices d'emploi...}

5 Ces baromètres sont particulièrement importants pour le marché de l'emploi aussi, puisque, traditionnellement, le Mittelstand occupe quelque $70 \%$ des actifs outre-Rhin, forme $80 \%$ des apprentis et est le principal créateur d'emploi. Ainsi, au cours des trois dernières années, alors que le secteur public surtout réduisait massivement ses effectifs, les PME ont créé 2,2 millions d'emplois, majoritairement des emplois réguliers (c'est-à-dire à temps plein et soumis à cotisations sociales). 77,3\% des entreprises interrogées disent ainsi avoir embauché des nouveaux salariés à temps plein. La plus forte demande en main-d'œuvre s'observe dans les services: 27,5\% des PME du tertiaire ont accru leurs effectifs, alors que 11,9\% seulement ont été contraintes de les comprimer, soit un solde positif de 15,6 points. Dans la production manufacturière, le solde est lui aussi largement positif (14,8 points), bien plus que dans le commerce (7,7points seulement). Toutes branches confondues, les PME les plus actives à l'embauche sont les plus jeunes (moins de deux ans d'existence) : elles ont été $35 \%$ à accroître leurs effectifs. A l'inverse, les plus âgées (plus de dix ans) ne l'ont fait que dans la proportion de $22 \%$.

\section{... mais sont plus prudentes, y compris pour l'investissement}

6 Toutes se montrent désormais plus prudentes - en matière d'embauche comme d'investissements. $46 \%$ seulement d'entre elles prévoient d'investir dans le semestre à venir (49,9\% l'an dernier). C'est plus par anticipation d'une demande ralentie que par manque de fonds : la part des PME à taux élevé de capitaux propres (plus de $30 \% \mathrm{du}$ total bilan) est montée à $26,9 \%$ (+3,4 point). (IB) 
INDEX

Mots-clés : compétitivité, concurrence, conjoncture, crise financière entreprise, Mittelstand, PME 